This PDF is a selection from a published volume from the National Bureau of Economic Research

Volume Title: Managing Currency Crises in Emerging Markets

Volume Author/Editor: Michael P. Dooley and Jeffrey A.

Frankel, editors

Volume Publisher: University of Chicago Press

Volume ISBN: 0-226-15540-4

Volume URL: http://www.nber.org/books/dool03-1

Conference Date: March 28-31, 2001

Publication Date: January 2003

Title: Interest Rates and Exchange Rates in the Korean, Philippine, and Thai Exchange Rate Crises

Author: Dongchul Cho, Kenneth D. West

URL: http://www.nber.org/chapters/c9645 


\title{
Interest Rates and Exchange Rates in the Korean, Philippine, and Thai Exchange Rate Crises
}

\author{
Dongchul Cho and Kenneth D. West
}

\subsection{Introduction}

A standard policy prescription in exchange rate crises is to tighten monetary policy, at least until the exchange rate has stabilized. Indeed, in the East Asian countries whose currencies collapsed in 1997, interest rates were raised, usually quite dramatically. For example, short-term rates rose from 12 to 30 percent in the space of a month in December 1997 in South Korea. The successful recovery from the crisis may seem to vindicate this policy.

However, that is not clear. High interest rates weaken the financial position of debtors, perhaps inducing bankruptcies in firms that are debt constrained only because of informational imperfections. The countries might have recovered, perhaps with less transitional difficulty, had an alternative, less restrictive, policy been followed. This has been argued forcefully by, for example, Furman and Stiglitz (1998) and Radelet and Sachs (1998).

There is mixed empirical evidence on the relationship between interest and exchange rates, even for developed countries (Eichenbaum and Evans 1995; Grilli and Roubini 1996). For countries that have undergone currency crises, Goldfajn and Gupta (1999) found that, on average, dramatic increases in interest rates have been associated with currency appreciations. However, there was no clear association for a subsample of countries that have undergone a banking crisis along with a currency crisis. This subsample includes the East Asian countries.

Dongchul Cho is a research fellow at the Korea Development Institute. Kenneth D. West is professor of economics at the University of Wisconsin and a research associate of the National Bureau of Economic Research.

The authors thank Akito Matsumoto, Mukunda Sharma, and Sungchul Hong for research assistance, and Robert Dekle, Gabriel Di Bella, and conference participants for helpful comments. West thanks the National Science Foundation for financial support. 
Papers that focus on the 1997 currency crises in East Asia also produce mixed results. Representative results from papers using weekly or daily data are as follows. Goldfajn and Baig (1998) decided that the evidence is mixed but on balance favor the view that higher interest rates were associated with appreciations in Indonesia, Korea, Malaysia, the Philippines, and Thailand. Cho and West (2000) concluded that interest rate increases led to exchange rate appreciation in Korea during the crisis. Dekle, Hsiao, and Wang (2001) found sharp evidence that interest rate changes are reducedform predictors of subsequent exchange rate appreciations in Korea, Malaysia, and Thailand, though with long and variable lags. Finally, Gould and Kamin (2000) were unable to find a reliable relationship between interest rates and exchange rates in the five countries.

This paper conducts an empirical study of the relationship between exchange rates and interest rates during the 1997-98 exchange rate crises in Korea, the Philippines, and Thailand. Our central question is: in these economies, did exogenous monetary-policy-induced increases in the interest rate cause exchange rate depreciation or appreciation? Our central contribution is to propose a model that identifies a monetary policy rule, in a framework general enough to allow either answer to our central question. Our starting point is the observation that the sign of the correlation between exchange and interest rates - used in many previous studies to decide whether an increase in interest rates causes an exchange rate appreciationwill be sufficient to answer our question only if monetary policy shocks are the dominant source of movements in exchange and interest rates. Since shocks to perceived exchange rate risk are also arguably an important source of variability during an exchange rate crisis, one must specify a model that allows one to distinguish the effects of the two types of shocks.

We do so with a model that has two equations and is linear. One equation is interest parity, with a time-varying risk premium. Importantly, we allow the risk premium to depend on the level of the interest rate. The second equation is a monetary policy rule, with the interest rate as the instrument. The two variables in the model are the exchange rate and domestic interest rate. These two variables are driven by two exogenous shocks, a monetary policy shock and a shock to the component of the exchange rate risk premium not dependent on the level of the interest rate. The model has two key parameters. One parameter $(a)$ indexes how strongly the monetary authority leans against incipient exchange rate movements. The other parameter (d) indexes the sensitivity of exchange rate risk premiums to the level of interest rates.

Whether interest rates should be increased or decreased to stabilize a depreciating exchange rate depends on how sensitive risk premiums are to interest rates. Interest rates should be increased unless risk premiums are strongly increasing with the level of the interest rate. This is the orthodox policy. Interest rates should be lowered if risk premiums are strongly posi- 
tively related to the interest rate. This is the view of Furman and Stiglitz (1998). Our model precisely defines "strongly positive" as meaning that the parameter $d$ referenced in the previous paragraph is greater than 1 .

According to our model, the sign of the correlation between exchange and interest rates suffices to reveal whether exogenous increases in interest rates led to exchange rate appreciation only if shocks to monetary policy dominate the movement of exchange and interest rates. Suppose instead that shocks to the exchange rate risk premium are the primary source of movements in exchange and interest rates. Then in our model, the correlation between the two variables may be positive even if, in the absence of risk premium shocks, increases in interest rates would have stabilized a depreciating exchange rate (i.e., $d<1$ ). (We measure exchange rates so that a larger value means depreciation. Thus, a positive correlation means that high interest rates are associated with a depreciated exchange rate.) The correlation between the two may be negative even if interest rate increases would have destabilized exchange rates (i.e., $d>1$ ) in the absence of risk premium shocks.

Using a special case of our model, we find that exchange rate risk premiums in Korea were inversely related to the level of interest rates. In the Philippines, risk premiums were increasing in interest rates, though modestly so. In both these countries, stabilization required raising interest rates. In Thailand, on the other hand, risk premiums were strongly increasing, in the precise sense that the parameter referenced in the preceding paragraph was estimated to be greater than 1. Accordingly, ceteris paribus, an exogenous increase in the interest rate led to exchange rate appreciation in Korea and the Philippines, and exchange rate depreciation in Thailand.

Unfortunately, confidence intervals for model parameters are huge. They do not rule out the possibility that interest rate increases led to depreciation in Korea and the Philippines, to appreciation in Thailand. To a certain extent this seems to follow unavoidably from the fact that our sample sizes are small, as is suggested by the similarly weak evidence found in most of the papers cited above. A second reason our results are tentative is that for tractability and ease of interpretation we base our inference particularly simple assumptions about the behavior of unobservable shocks. These assumptions are roughly consistent with the data, but alternative, more complex models no doubt would fit better. Moreover, we use an inefficient estimation technique. A final reason our results are tentative is that we do not allow for the possibility of destabilizing monetary policy, that is, a period during which a monetary authority moved interest rates in a destabilizing direction, perhaps before adopting a policy that ultimately led to exchange rate stabilization. We leave all such tasks to future research.

We also leave to future research the larger, and more important, issue about what constitutes good policy in an exchange rate crisis. High interest rates may be bad policy even if they stabilize exchange rates, and may be good policy even if they do not. We believe that our paper contributes to our 
understanding the larger issue, since any policy analysis must take a stand on the interest rate-exchange rate relationship. In our own work, brief discussions of policy during the Korean crisis may be found in Cho and Hong (2000) and Cho and West (1999).

Section 1.2 describes our model, section 1.3 our data, and section 1.4 our results. Section 1.5 concludes. An appendix contains some technical details.

\subsection{Model}

Our simple linear model has three equations and two observable variables. The three equations are interest parity, a relationship between exchange rate risk and interest rates, and an interest rate reaction function (monetary policy rule). The two variables are the domestic interest rate and the exchange rate.

We write interest parity as

$$
i_{t}=i_{t}^{*}+E_{t} s_{t+1}-s_{t}+d_{t} .
$$

In equation (1), $i_{t}$ and $i_{t}^{*}$ are (net) domestic (i.e., Asian) and foreign nominal interest rates; $s_{t}$ is $100 \times \log$ of the nominal spot exchange rate, with higher values indicating depreciation; $E_{t}$ denotes expectations; $d_{t}$ is a risk premium. If $d_{t} \equiv 0$, equation (1) is uncovered interest parity. The variable $d_{t}$, which may be serially correlated, captures default risk as well as the familiar premium due to risk aversion.

It presumably is safe to view $i_{t}^{*}$ as substantially unaffected by domestic (Asian) monetary policy. The same cannot be assumed for $E_{t} s_{t+1}, s_{t}$, and $d_{t}$, all of which are determined simultaneously with $i_{t}$. However, for the moment we follow some previous literature (e.g., Furman and Stiglitz 1998) and perform comparative statics using equation (1) alone. Evidently, if $i_{t}$ is increased, but $E_{t} s_{t+1}$ and $d_{t}$ are unchanged, then $s_{t}$ must fall (appreciate): the orthodox relationship. If, as well, increases in interest rates today cause confidence that the exchange rate will stay strong (i.e., that $s_{t+1}$ will be lower than it would have been in the absence of an interest rate hike), then $s_{t}$ must fall even farther for equation (1) to hold.

However, this channel will be offset insofar as increases in $i_{t}$ are associated with increases in $d_{t}$. Such a rise may come about because higher interest rates are associated with higher default rates, or because higher interest rates raise risk premiums. This, in turn, may lead to expectations of depreciation (increase) in $s_{t+1}$. Furman and Stiglitz (1998) argue on this basis that equation (1) alone does not tell us even whether increases in $i_{t}$ will be associated with increases or decreases in $s_{t}$, let alone the magnitude of the change.

We agree with this argument. Our aim is to specify a model that allows for the possibility of either a positive or negative response of $s_{t}$ to an exogenous monetary-policy-induced increase in $i_{t}$, and then to estimate the model 
to quantify the sign and size of the effect. To that end, we supplement the interest parity condition in equation (1) with two additional equations. The first is a simple monetary policy rule. We assume that the nominal interest rate is the instrument of monetary policy. During a period of exchange rate crisis, the focus of monetary policy arguably is on stabilizing the exchange rate. We therefore assume

$$
i_{t}=a\left(E_{t-1} s_{t}-\bar{s}_{t}\right)+\tilde{u}_{m t} .
$$

In equation (2), $a$ is a parameter, and $\bar{s}_{t}$ is the target exchange rate. Conventional interpretation of International Monetary Fund (IMF) policy is that the IMF argues for $a>0$. This means that the monetary authority leans against expected exchange rate depreciations. Of course, $a<0$ means that the monetary authority lowers the interest rate in anticipation of depreciation. For simplicity, we impound the target level into the unobservable disturbance $\tilde{u}_{m t}$. Upon defining $u_{m t}=\tilde{u}_{m t}-a \overline{s_{t}}$, equation (2) becomes

$$
i_{t}=a E_{t-1} s_{t}+u_{m t} \text {. }
$$

The variable $u_{m t}$, which may be serially correlated, captures not only changes in the target level of the exchange rate, but all other variables that affect monetary policy. Ultimately it would be of interest to model $u_{m t}$ 's dependence on observable variables such as $i_{t}^{*}$ and the level of foreign reserves; once again, we suppose that in the crisis period it is reasonable to focus on the exchange rate as the dominant determinant of interest rate policy. The "exogenous monetary policy induced increase in $i_{t}$ " referenced in the previous paragraph is captured by a surprise increase in $u_{m t}$.

Note the dating of expectations: period $t$ expectations appear in equation (1), period $t-1$ expectations in equation $\left(2^{\prime}\right)$. This reflects the view that asset market participants, whom we presume to be setting exchange rates, react more quickly than does the monetary authority to news about exchange rate risk premiums (i.e., to shocks to the variable that we call $u_{d t}$, below). Capturing this view by using $t-1$ expectations in the monetary rule is most appealing when data frequency is high. Accordingly, we assume daily decision making, and allow for the effects of time aggregation when we estimate our model using weekly data. Of course, we do not literally believe that in setting the interest rate each day the monetary authority is ignorant of intraday developments. Rather, we take this as a tractable approximation.

The final equation is one that relates the risk premium $d_{t}$ to the interest rate $i_{t}$.

$$
d_{t}=d i_{t}+\tilde{u}_{d t}
$$

Equation (3) is an equilibrium relationship between risk premiums and interest rates. In the conventional view, $d<0$, in which case higher interest rates are associated with lower risk, or perhaps $d=0$, in which case there is no link between interest rates and risk. The $d<0$ interpretation seems con- 
sistent with Fischer (1998, 4), who argues that temporarily raising interest rates restores confidence. In an alternative view, such as that of Furman and Stiglitz (1998), $d \gg 0$, and higher interest rates are associated with higher risk. We suppose that $d$ is structural, in the sense that one can think of $d$ as remaining fixed while one varies the monetary policy reaction parameter $a$. Obviously this cannot hold for arbitrarily wide variation in $a$, but perhaps is a tolerable assumption for empirically plausible variation in $a$.

The variable $\tilde{u}_{d t}$ captures all other factors that determine the risk premium. Ultimately it would be of interest to partially proxy $\tilde{u}_{d t}$ with observable variables. Candidate variables include the level of reserves and debt denominated in foreign currency (see Cho and West 2000) for the role such variables played in Korea). However, because such data are not available at high frequencies, for simplicity we treat $\tilde{u}_{d t}$ as unobservable and exogenous.

To simplify notation, and for consistency with our empirical work, we impound $i_{t}^{*}$ in the unobservable disturbance to interest parity, defining $u_{d t}=$ $i_{t}^{*}+\tilde{u}_{d t}$. We then combine equations (3) and (1) to obtain

$$
(1-d) i_{t}=E_{t} s_{t+1}-s_{t}+u_{d t} .
$$

Equations (2') and (4) are a two-equation system for the two variables $i_{t}$ and $s_{t}$. Upon substituting equation $\left(2^{\prime}\right)$ into equation (4) and rearranging, we obtain

$$
s_{t}+a(1-d) E_{t-1} s_{t}=E_{t} s_{t+1}+u_{d t}-(1-d) u_{m t} .
$$

Equation (5) is a first-order stochastic difference equation in $s_{t}$. To solve it, we assume homogeneous and model-consistent expectations. That is, we assume that private-sector and government expectations are consistent with one another, in that the variables used in forming $E_{t-1}$ in equations (2) and $\left(2^{\prime}\right)$ are the period $t-1$ values of the period $t$ variables used in forming $E_{t}$ in equations (1) and (4). Moreover, these expectations are consistent with the time series properties of $u_{d t}$ and $u_{m t}$. To make these assumptions operational, we assume as well that $E_{t}$ denotes expectations conditional on current and lagged values of $u_{d t}$ and $u_{m t}$ (equivalently, current and lagged values of $s_{t}$ and $i_{t}$ ).

Define $b=[1+a(1-d)]^{-1}$. We make the stability assumption $0<b<1$ and the "no bubbles" assumption $\lim _{j \rightarrow \infty} b^{j} E_{t-1} s_{t+j}=0$. The stability assumption requires

$$
a<0, d>1 \quad \text { or } \quad a>0, d<1 .
$$

The algebraic condition in equation (6) captures the following commonsense stability condition. Suppose risk premiums are so sensitive to interest rates that $d>1$. Stability then requires that the monetary authority lower interest rates $(a<0)$ in response to anticipated depreciations. For if it instead raised interest rates, we would have the following neverending spiral: A positive shock to the risk premium causes exchange rates to depreciate, 
which with $a>0$ causes the monetary authority to raise interest rates, which with $d>1$ causes a further depreciation and a further raising of interest rates. . . Similarly, if $d<1$, stability requires increasing interest rates in the face of anticipated depreciation. Note that one can have a stable system when $a>0$ even if $d>0$, as long as $d<1$ : In our model, a policy of leaning against exchange rate depreciations $(a>0)$ is stable even if increases in interest rates are associated with increased risk $(d>0)$, as long as the increase in risk is not too large $(d<1)$.

To solve the model, project both sides of equation (5) onto period $t-1$ information, and then solve recursively forward. The result is

$$
E_{t-1} s_{t}=b \sum_{j=0}^{\infty}\left\{b^{j} E_{t-1}\left[u_{d t+j}-(1-d) u_{m t+j}\right]\right\} .
$$

For given processes of $u_{d t}$ and $u_{m t}$, we can solve for $E_{t-1} s_{t}$ using equation (7). Putting this solution into equation ( $\left.2^{\prime}\right)$ yields $i_{t}$, which in turn may be used in equation (4) to solve for $s_{t}$.

The data we use are to a certain extent consistent with a random walk for both $u_{m t}$ and $u_{d t}$, say,

$$
u_{m t}=u_{m t-1}+e_{m t}, \quad u_{d t}=u_{d t-1}+e_{d t} .
$$

Such shocks make for quick, one-period movements from one steady state to another in response to a shock. They are special in other ways as well, as noted below. Under the assumption that $e_{m t}$ and $e_{d t}$ are uncorrelated with one another, figures 1.1-1.4 plot responses of $i_{t}$ and $s_{t}$ to 1 percent increases in $e_{m t}$ and $e_{d t}$, for each of four parameter sets: $a=0.2, d=-9 ; a=0.7, d=$ $-9 ; a=0.7, d=0.6 ; a=-0.5, d=1.2$.

Figure 1.1 plots the response of $i_{t}$ to a 1 percent increase in $e_{m t}$. Only one line is plotted because for all four parameter sets, response is identical. As is obvious from equation $\left(2^{\prime}\right)$, the impact response is a 1 percent increase. The interest rate then returns to initial value. That is, a permanent increase in $u_{m t}$ leads to a transitory change in $i_{t}$. Evidently, from equation $\left(2^{\prime}\right)$, in steady state $s_{t}$ must fall by $1 / a$ (i.e., rise by $-1 / a$ when $a<0$ ). This depicted in figure 1.2. Consider first the case in which $a>0$. Then an exogenous in-

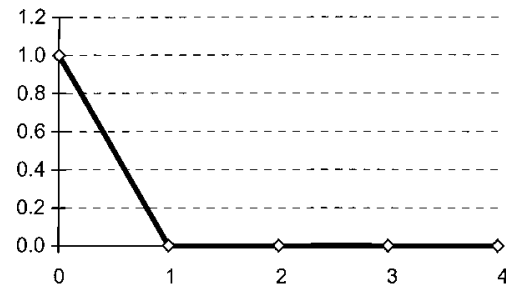

Fig. 1.1 Response of $i_{t}$ to a 1 percent shock to $e_{m t}$

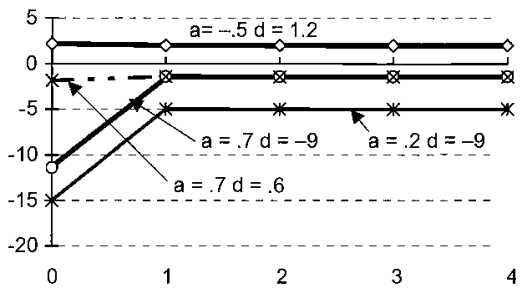

Fig. 1.2 Response of $s_{t}$ to a 1 percent shock to $e_{m t}$ 


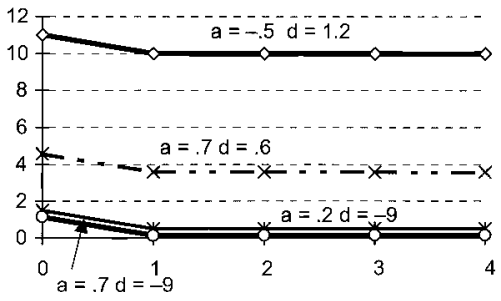

Fig. 1.3 Response of $s_{t}$ to a 1 percent shock to $e_{d t}$

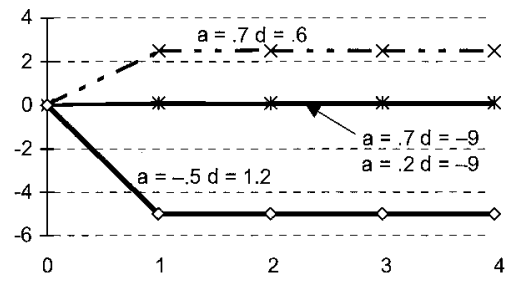

Fig. 1.4 Response of $i_{t}$ to a 1 percent shock to $e_{d t}$

crease in the interest rate causes an exchange rate appreciation: with $a>0$, exogenous increases in interest rates stabilize a depreciating exchange rate. In the three specifications with $a>0$, the impact elasticity ranges from about -2 to -15 . For given $d$, the impact effect is smaller for $a=0.7$ than for $a=0.2$ : larger $a$ means a harsher monetary policy response and greater exchange rate stability. On the other hand, when $a<0$, an exogenous increase in the interest rate causes the exchange rate to depreciate.

These long responses are of course consistent with long-run neutrality of monetary policy. An increase in $e_{m t}$ means a commitment to raise the interest rate for any given expected level of exchange rates, now and forever. Because the level of the exchange rate adjusts in the long run, there is no long-run effect on the rate of exchange rate depreciation, and therefore no long-run effect on the level of the interest rate.

Figure 1.3 depicts the response of $s_{t}$ to a 1 percent increase in the risk premium. In all specifications, the exchange rate increases in both the short and the long run. The impact effect is greater than the long-run effect because according to equation $\left(2^{\prime}\right)$ it takes a period before interest rates respond to the increased risk. For given $d$, the response is less for larger $a$; for given $a$, the response is greater for larger $d$.

Figure 1.4 plots the response of $i_{t}$ to a 1 percent increase in the risk premium. By assumption, there is no contemporaneous response. When $a>0$, the interest rate is increased; when $a<0$, it is decreased. When $a$ is larger in absolute value, there is a larger increase. In accordance with equation (4), the long-run response of $i_{t}$ is $1 /(1-d)$, and thus it is governed only by $d$ but not $a$; in the simple random-walk specification, the long run is achieved in one period and so the responses for $(a=0.2) /(d=-9)$ and $(a=0.7) /(d=$ $-9)$ are identical.

Some implications of the above are worth noting. First, upon comparing the figures, we see that when $a>0$, risk premium shocks cause interest and exchange rates to move in the same direction, while monetary shocks cause them to move in opposite directions. For $a<0$, risk premium shocks cause interest and exchange rates to move in the opposite direction, while monetary shocks cause them to move in the same direction. This result holds not 
only for random-walk shocks but also for arbitrary stationary AR(1) shocks.

The implication is that the sign of the correlation between interest and exchange rates is not sufficient to tell us that interest rate hikes stabilized a depreciating currency. A negative correlation may result when $a<0$ because the data are dominated by risk premium shocks. A positive correlation may result when $a>0$ because the data are dominated by risk premium shocks.

Second, suppose one takes $a$ as a choice parameter for a monetary authority that aims to stabilize a rapidly depreciating exchange rate. If exchange rate risk does not rapidly increase with the level of interest rates $(d$ $<1$ ), then the monetary authority should raise interest rates (set $a>0$ ) when further depreciation is expected. However, if exchange rate risk does rapidly increase with the level of interest rates $(d>1)$, then the monetary authority should lower interest rates (set $a<0$ ) when further depreciation is expected. In either case, stabilization smoothes exchange rates.

A third point is that with random-walk shocks - an assumption we maintain in our empirical work - this stabilization of exchange rates will induce a negative first-order autocorrelation in $\Delta s_{t}$. That is, smoothing in the face of random-walk shocks causes exchange rates to exhibit some mean reversion relative to a random-walk benchmark. (Our model is capable of generating positive autocorrelation in $\Delta s_{t}$, but only if the shocks exhibit dynamics beyond that of a random walk.)

Finally, with random-walk shocks, one can read the sign of $1-d$, and hence whether $d$ is above or below the critical value of 1 , directly from the sign of the correlation between $\Delta i_{t}$ and $\Delta s_{t-1}$. When $d$ is less than 1, this correlation is positive; when $d$ is greater than 1, this correlation is negative: If stabilization involves increasing (decreasing) interest rates in response to incipient exchange rate depreciations, then, naturally, $\Delta i_{t}$ will be positively (negatively) correlated with $\Delta s_{t-1}$. Again, this simple result applies because we assume random-walk shocks and need not hold for richer shock processes.

\subsection{Data and Estimation Technique}

We obtained daily data for Korea, the Philippines, and Thailand, either directly from Bloomberg or indirectly from others who reported Bloomberg as the ultimate source. The mnemonics for exchange rates are KRW (Korea), PHP (the Philippines), and THB (Thailand). The mnemonics for interest rates are KWCRIT (Korea), PPCALL (the Philippines: Philippine Peso Interbank Call Rate), and BITBCALL (Thailand: Thai STD Chartered Bank Call Rate). Because many days were missing, we constructed weekly data by sampling Wednesday of each week. If Wednesday was not available we used Thursday; if Thursday was not available we used Tuesday. Interest rates are expressed at annual rates; exchange rates are versus the U.S. dollar. 
We start our samples so that we are two weeks into what arguably can be considered the postcrisis exchange rate targeting regime. Two weeks allows both the current and lagged value of interest and exchange rate differences to fall inside the new regime. For Thailand and the Philippines, this means a start date of Wednesday, 23 July 1997. (As noted above, our weekly data are for Wednesday.) For Korea, the date is Wednesday, 17 December 1997. We ended our samples one year later (sample size of 53 weeks), since the simple monetary rule (eq. [2]) probably did not well describe policy once the countries had stabilized. We also tried 27 -week samples, with little change in results. Figures 1.5-1.7 plot our data, in levels. The dashed lines delimit our one-year samples.

Formal unit root tests failed to reject the null of a unit root. Hence, we examine interest and $(\log )$ exchange rates in first differences. We failed to find cointegration between $i_{t}$ and $s_{t}$. (Using similar weekly data, Gould and Kamin 2000 and Dekle, Hsiao, and Wang 2001 also failed to find cointegration.) Hence, in our regression work (mentioned briefly below) we estimated a vector autoregression (VAR) in $\Delta i_{t}$ and $\Delta s_{t}$ without including an error correction term. We note in passing that the lack of cointegration meant that we could not turn to estimation of a cointegrating vector to identify the monetary policy parameter $a$.

To identify $a$ and $d$, we assume that $u_{m t}$ and $u_{d t}$ follow random walks. In this case, our model implies a vector MA(1) process for $\left(\Delta i_{t}, \Delta s_{t}\right)^{\prime}$, which, as explained in the next section, is more or less consistent with our data. We allow the innovations in $u_{m t}$ and $u_{d t}$ to be contemporaneously correlated. Such a correlation might result, for example, if the level of foreign reserves importantly affected both monetary policy and exchange rate risk. Because we allow this correlation, it will not be meaningful to decompose the variation of exchange or interest rates into monetary and risk components. (We do not, however, model or exploit cross-country correlations in $u_{d t}$ or $u_{m t}$, deferring to future work the attractive possibility of using information in such correlations.) We allow for decisions to be made daily rather than weekly. That is, we assume that the model described in section 1.2 generates the data with a time period corresponding to one day. However, we sample the data only once every five observations.

We use five moments to compute the five parameters $a$ and $d$ and the three elements of the variance-covariance matrix of $\left(e_{m t}, e_{d t}\right)^{\prime}$. The moments we used included three chosen because they were estimated relatively precisely: $\operatorname{var}\left(\Delta i_{t}\right)$, var $\left(\Delta s_{t}\right)$ and corr $\left(\Delta i_{t}, \Delta s_{t}\right)$. The final two moments used, corr $\left(\Delta i_{t}\right.$, $\left.\Delta s_{t-1}\right)$ and corr $\left(\Delta s_{t}, \Delta s_{t-1}\right)$, were largely chosen for clarity and convenience. As explained at the end of section 1.2 above, our model has simple and direct implications for the signs of these correlations. As a technical matter, with this choice of moments, the parameters could be solved for analytically, although the equations are nonlinear.

An appendix gives details on how we mapped moments into parameters. 


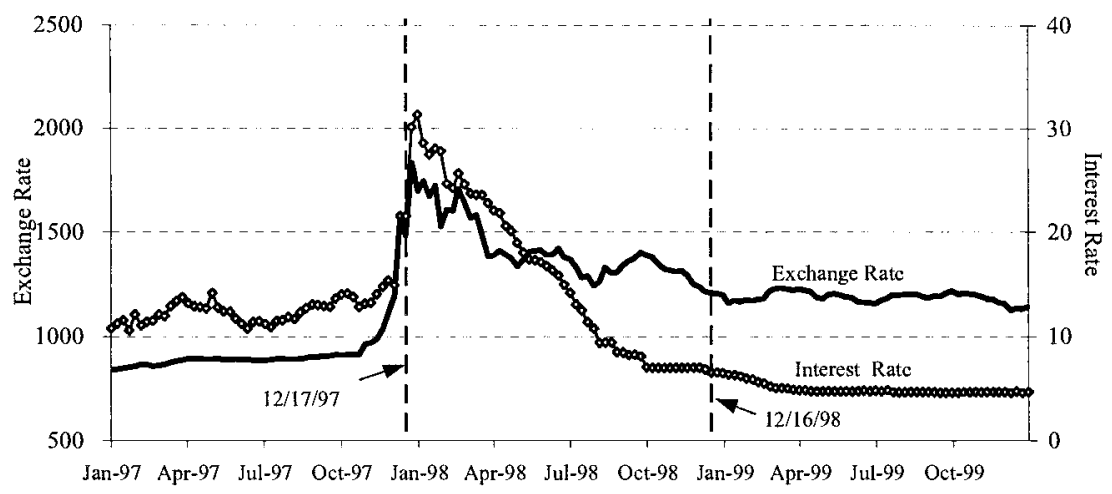

Fig. 1.5 Overnight interest rate and won/dollar exchange rate, Korea

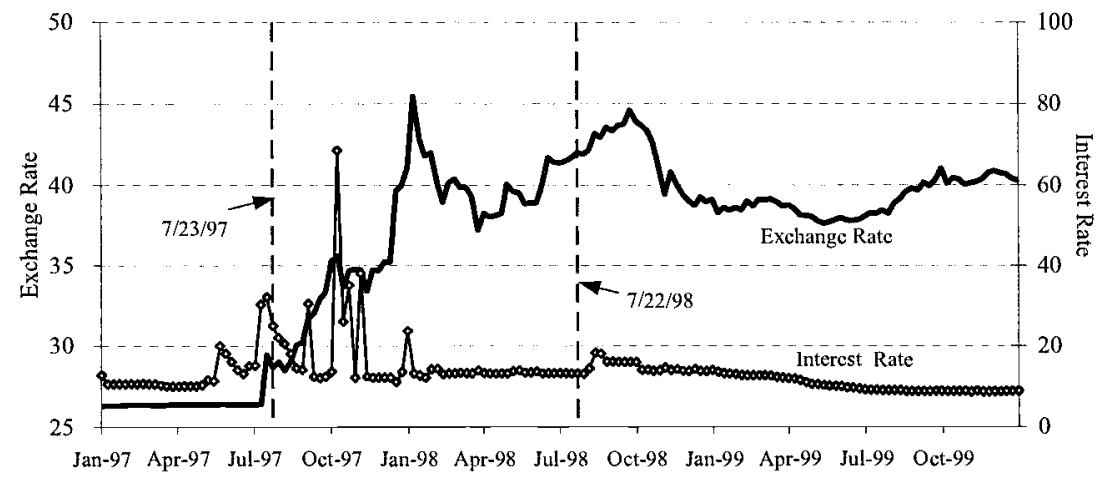

Fig. 1.6 Overnight interest rate and peso/dollar exchange rate, the Philippines

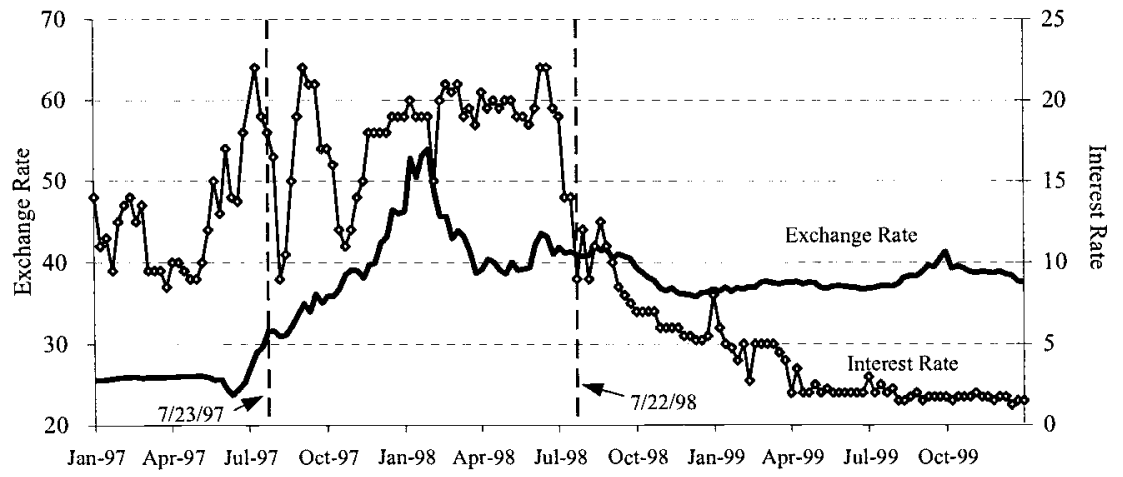

Fig. 1.7 Overnight interest rate and baht/dollar exchange rate, Thailand 
Two points about the mapping are worth noting here. The first is that since the five equations are nonlinear, in principle they can yield no reasonable solutions. For example, for a given set of moments, the implied value of the variance of $e_{d t}$ might be negative. The second is that our algorithm solves for $a$ from a root to a quadratic. If the estimated first-order autocorrelation of $\Delta s_{t}$ is between -0.5 and 0 , this quadratic is guaranteed to have two real roots, one implying a positive value of $a$, the other a negative value. We chose the root consistent with stability: the root implying a positive value of $\hat{a}$ if $\hat{d}<1$, a negative value if $\hat{d}<1$. (The solution algorithm is in part recursive, with $d$ estimated prior to $a$.) We made this choice because an unstable solution implies explosive data, at least if the unstable policy is expected to be maintained indefinitely; this is inconsistent with our use of sample moments.

We report 90 percent confidence intervals. These are "percentile method" intervals, constructed by a nonparametric bootstrap using block resampling with nonoverlapping blocks. Details are in the appendix.

\subsection{Empirical Results}

Table 1.1 has variances and auto- and cross-correlations for lags 0,1 , and 2 , with the bootstrap confidence intervals in parentheses. A skim of the table reveals that virtually all the auto- and cross-correlations are insignificantly different from zero at the 10 percent level. The only exceptions are the correlations between $\Delta s_{t}$ and $\Delta i_{t-1}$ in the shorter sample in Korea, between $\Delta i_{t}$ and $\Delta i_{t-1}$ in the longer sample in the Philippines, and between $\Delta i_{t}$ and $\Delta s_{t}$ in both samples in Thailand. (We did not report confidence intervals for $\operatorname{var}\left[\Delta i_{t}\right]$ and $\operatorname{var}\left[\Delta s_{t}\right]$ in table 1.1; all point estimates of these variances were significant at the 90 percent level-indeed, at any significance level-by construction.)

The insignificance of the point estimates at lag 2 is consistent with a vector MA(1) process for $\left(\Delta i_{t}, \Delta s_{t}\right)^{\prime}$, because population auto- and crosscorrelations will all be zero for lags 2 and higher for such a process. This is the main sense in which a random walk for $u_{m t}$ and $u_{d t}$ implies a process more or less consistent with the data. As well, the estimates of the first-order autocorrelation of $\Delta s_{t}$ is negative in all samples, though barely so for the Philippines and Thailand in the one-year samples (point estimates $=-0.07$ and -0.02); as noted in section 1.2 above, a negative autocorrelation is implied by our model if shocks are random walks.

On the other hand, the insignificance of the point estimates at lag 1, and of the contemporaneous correlation between $\Delta i_{t}$ and $\Delta s_{t}$ in Korea and the Philippines, is bad news for our MA(1) model, and, in our view, for any empirical study of these data. Because the data are noisy, estimates of model parameters - which of course will be drawn from moments such as those reported in table 1.1 -will likely be imprecise. That, perhaps, is an inevitable 


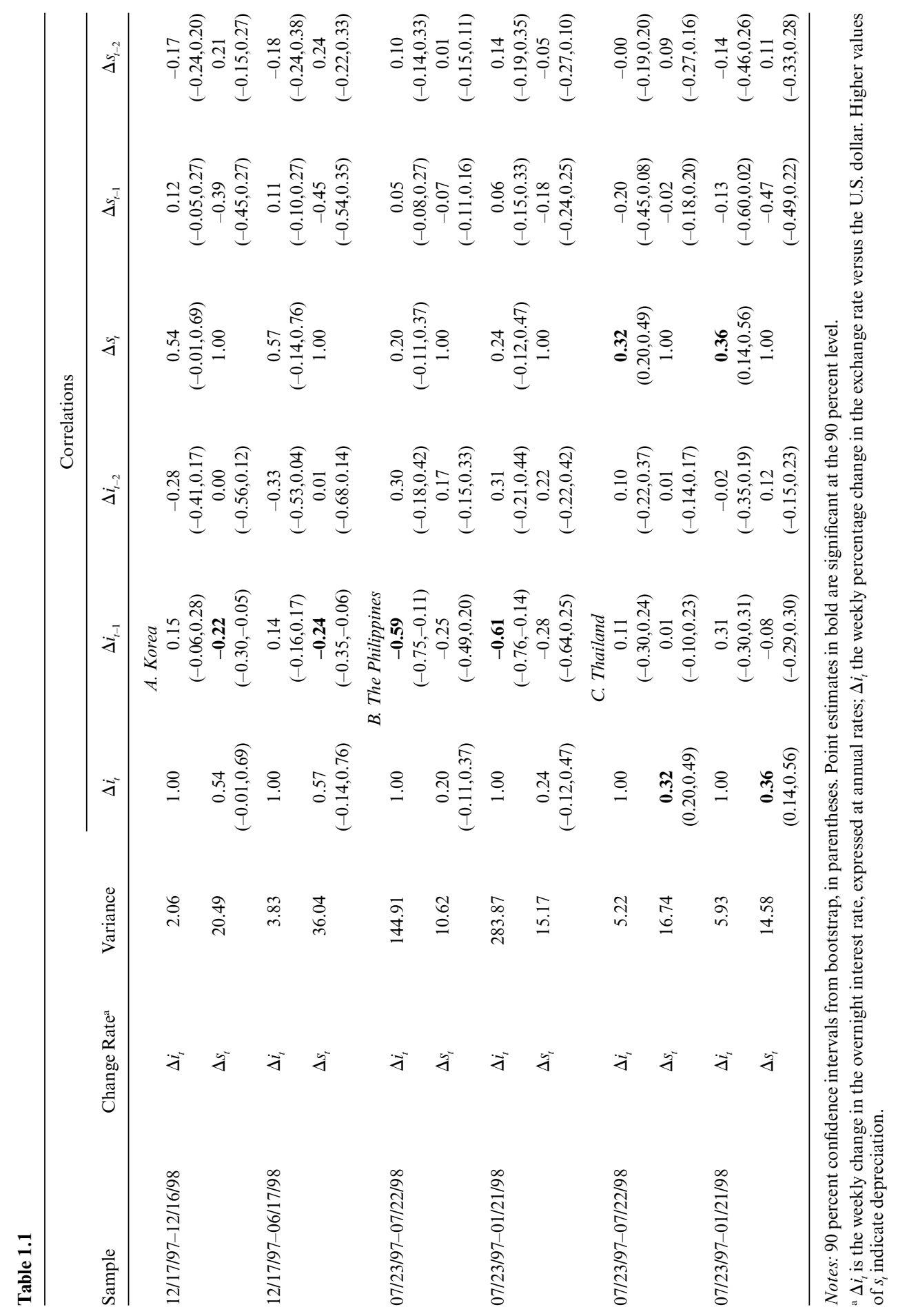


consequence of our decision to focus on a sample small enough that it a priori seemed likely to have a more or less stable interest rate rule.

We note in passing that when a second-order VAR in $\left(\Delta i_{t}, \Delta s_{t}\right)$ is estimated for one-year samples, $F$-tests (not reported in the table) yield slightly sharper results. Specifically, the null of no predictability is rejected for lagged interest rates in the $\Delta i_{t}$ equation in the Philippines and for lagged exchange rate changes in both the $\Delta i_{t}$ and the $\Delta s_{t}$ equations in Korea but not otherwise. This suggests the importance of allowing for richer dynamics in the shocks, an extension suggested as well by the fact that the absolute value of the Philippine estimate of corr $\left(\Delta i_{t}, \Delta i_{t-1}\right)$ is greater than 0.5 , a magnitude inconsistent with $\Delta i_{t}$ following an MA(1) process. We leave that as a task for future research.

Using the algorithm described in the appendix and the previous section, we estimated $a$ and $d$ from some moments reported in table 1.1. (The algorithm also automatically produces estimates of the variance-covariance matrix of $\left(e_{m t}, e_{d t}\right)^{\prime}$, which we do not discuss because these are not of economic interest.) Columns (3) and (4) in table 1.2 present these estimates, again with 90 percent confidence intervals from a bootstrap given in parentheses. The algebraic values of the estimates of $d$ are lowest for Korea and highest for Thailand, with

$$
\hat{d} \text { for Korea }<0<\hat{d} \text { for Philippines }<1<\hat{d} \text { for Thailand. }
$$

\begin{tabular}{|c|c|c|c|c|c|}
\hline & \multirow[b]{2}{*}{$\begin{array}{l}\text { Sample } \\
\text { (1) }\end{array}$} & \multirow[b]{2}{*}{$\begin{array}{c}a \\
(2)\end{array}$} & \multirow[b]{2}{*}{$\begin{array}{c}d \\
(3)\end{array}$} & \multicolumn{2}{|c|}{$\begin{array}{c}\% \text { Response of } s_{t} \text { to a } 1 \% \\
\text { Shock to } u_{m t}\end{array}$} \\
\hline & & & & $\begin{array}{l}\text { Impact } \\
(4)\end{array}$ & $\begin{array}{l}\text { Long-Run } \\
\text { (5) }\end{array}$ \\
\hline \multirow[t]{2}{*}{ Korea } & $12 / 17 / 97-12 / 16 / 98$ & $\begin{array}{c}0.25 \\
(-0.05,0.35)\end{array}$ & $\begin{array}{c}-8.87 \\
(-27.7,14.2)\end{array}$ & $\begin{array}{c}-13.9 \\
(-43.9,36.3)\end{array}$ & $\begin{array}{c}-4.1 \\
(-15.2,12.1)\end{array}$ \\
\hline & $12 / 17 / 97-06 / 17 / 98$ & $\begin{array}{c}0.36 \\
(-0.12,0.37)\end{array}$ & $\begin{array}{c}-11.27 \\
(-27.7,39.4)\end{array}$ & $\begin{array}{c}-15.0 \\
(-46.8,61.7)\end{array}$ & $\begin{array}{c}-2.8 \\
(-20.6,17.0)\end{array}$ \\
\hline \multirow[t]{2}{*}{ The Philippines } & 07/23/97-07/22/98 & $\begin{array}{c}0.76 \\
(-1.77,5.76)\end{array}$ & $\begin{array}{c}0.57 \\
(-0.72,2.43)\end{array}$ & $\begin{array}{c}-1.8 \\
(-8.6,7.1)\end{array}$ & $\begin{array}{c}-1.3 \\
(-6.9,5.9)\end{array}$ \\
\hline & 07/23/97-01/21/98 & $\begin{array}{c}1.12 \\
(-2.70,9.04)\end{array}$ & $\begin{array}{c}0.31 \\
(-0.92,3.25)\end{array}$ & $\begin{array}{c}-1.6 \\
(-6.7,7.5)\end{array}$ & $\begin{array}{c}-0.9 \\
(-3.8,4.9)\end{array}$ \\
\hline \multirow[t]{2}{*}{ Thailand } & 07/23/97-07/22/98 & $\begin{array}{c}-0.54 \\
(-1.07,0.19)\end{array}$ & $\begin{array}{c}1.16 \\
(-2.25,7.74)\end{array}$ & $\begin{array}{c}2.0 \\
(-12.4,21.8)\end{array}$ & $\begin{array}{c}1.8 \\
(-9.0,15.1)\end{array}$ \\
\hline & 07/23/97-01/21/98 & $\begin{array}{c}-0.96 \\
(-1.33,0.11)\end{array}$ & $\begin{array}{c}6.59 \\
(-3.7,14.5)\end{array}$ & $\begin{array}{c}6.6 \\
(-13.8,23.4)\end{array}$ & $\begin{array}{c}1.0 \\
(-8.9,10.4)\end{array}$ \\
\hline
\end{tabular}

Notes: $a$ is a monetary policy reaction parameter defined in equation (2); $d$ measures the sensitivity of exchange rate risk premia to the interest rate, as defined in equations (1) and (3). 90 percent confidence intervals, from bootstrap, in parentheses. The elasticities in columns (5) and (6) are the response to a surprise, permanent 1 percent increase in $u_{m t}$ 
The implication is that in equilibrium, increases in interest rates were associated with decreases in exchange rate risk in Korea. The association between interest rates and exchange rate risk was positive in the Philippines, but sufficiently small that if monetary policy is to be stabilizing, interest rates must be increased in response to expected exchange rate depreciations $(a>0)$. The association is also positive in Thailand, with the estimated value of $d$ greater than 1 . Hence if monetary policy is to be stabilizing in Thailand, interest rates must be decreased in response to expected exchange rate depreciations $(a<0)$. As explained above, the signs of $\hat{d}$ follow from the signs of the estimates of the correlation between $\Delta i_{t}$ and $\Delta s_{t-1}$; negative in Thailand, positive in Korea and the Philippines.

As we feared, the confidence intervals on the estimates of $a$ and $d$ are large; indeed, they are staggeringly large. Using a two-tailed test, one can reject the null that $a=0$ in Korea in the one-year sample at the 16 percent level (not reported in the table); all other parameters are even more imprecisely estimated.

Let us abstract from the confidence intervals and focus on the point estimates. We do not know of estimates from other studies that can be used to gauge directly the plausibility of the estimate of $d$. This ranking does conflict with Barsuto and Ghosh (2000), who concluded that real interest rate hikes increased the exchange rate risk premium in Korea, decreased it in Thailand. (Barsuto and Ghosh did not study the Philippines.) On the other hand, it is our sense that the ranking in equation (9) accords with the view that fundamentals were best in Korea, worst in Thailand. Moreover, the bottom-line conclusion - that interest rate increases caused depreciation in Thailand, appreciation in Korea and the Philippines - is consistent with Goldfajn and Baig (1998, table 3, full sample estimates) and with Di Bella's (2000) findings for Thailand (Di Bella does not consider other Asian countries).

For all practical purposes, impulse responses to orthogonal movements in $e_{m t}$ and $e_{d t}$ are given in figures 1.1-1.4. For Korea, see the lines for $a=0.2$, $d=-9$; for the Philippines, see $a=0.7, d=0.6$; for Thailand, see $a=0.5, d$ $=1.2$. The exact responses of $s_{t}$ to a 1 percent positive value of $e_{m t}$ are given in columns (5) and (6) of table 1.2. Once again, the confidence intervals are very large, as is inevitable since these elasticities are simple transformations of the estimates of $a$ and $d$.

Now, Thailand's agreements with the IMF called for Thailand to maintain interest rates in indicative ranges that were high relative to precrisis levels (e.g., 12-17 percent in the August 1997 agreement [IMF 1997a, annex B], 15-20 percent in the December 1997 agreement [IMF 1997b, annex B]. Some agreements also suggested raising interest rates when the exchange rate is under pressure (IMF 1997b, 1998). How can this be reconciled with our Thai estimates $(\hat{a}<0, \hat{d}>1)$, which indicate that the stabilization was 
accomplished by lowering interest rates in the face of incipient depreciation? One interpretation is that IMF increases appear in our data as occasional and very visible large positive values of $u_{m t}$; most of the day-to-day systematic component of policy implicitly lowered interest rates in the face of incipient exchange rate depreciation, despite the agreement to raise interest rates when the exchange rate was pressured. On this interpretation, the appreciation would have occurred sooner absent the early increases in interest rates. A second interpretation is that policy did raise interest rates in the face of depreciation, both in the form of one-time increases early in the sample, and systematically throughout the sample. However, sampling error caused the estimate of $d$ to be greater than 1 and thus the estimate of $a$ to be negative. (We refer to $\hat{d}$ rather than $\hat{a}$ because $\hat{a}$ is solved from a quadratic with one negative and one positive root, and we choose the root consistent with stability: the root that yields $\hat{a}<0$ when $\hat{d}>1$, the root that yields $\hat{a}>0$ when $\hat{d}<1$. See section 1.3 and the appendix.)

We do not have any direct evidence on either of these interpretations. We hoped that some indirect evidence might be found by rolling the samples forward, recomputing the estimates of $a$ and $d$. Table 1.3 presents results of such an exercise, for one-year samples, and for all three countries. We dropped the initial observation as we added a final observation, keeping the sample at $T=53$ weeks. In Korea and Thailand, we stopped the process when the estimated first-order autocorrelation of $\Delta s_{t}$ turned positive. That date does not occur until January 1998 for the Philippines, and so to conserve space we stopped at September 1997.

The estimates for the Philippines and Thailand move little—surprisingly

Table 1.3

Rolling Sample Estimates of $a$ and $d$

\begin{tabular}{|c|c|c|c|c|c|c|c|c|}
\hline \multicolumn{3}{|c|}{ Korea } & \multicolumn{3}{|c|}{ The Philippines } & \multicolumn{3}{|c|}{ Thailand } \\
\hline Start & $\hat{a}$ & $\hat{d}$ & Start & $\hat{a}$ & $\hat{d}$ & Start & $\hat{a}$ & $\hat{d}$ \\
\hline $12 / 17 / 97$ & 0.24 & -8.99 & 07/23/97 & 0.74 & 0.57 & 07/23/97 & -0.53 & 1.16 \\
\hline $12 / 24 / 97$ & 0.48 & -3.37 & $07 / 30 / 97$ & 0.68 & 0.54 & $07 / 30 / 97$ & -0.54 & 1.12 \\
\hline $12 / 31 / 97$ & 0.41 & -1.82 & 08/06/98 & 0.68 & 0.55 & 08/06/98 & -0.54 & 1.13 \\
\hline 01/07/98 & 0.29 & -2.28 & 08/13/98 & 0.63 & 0.55 & 08/13/98 & -0.52 & 1.14 \\
\hline $01 / 14 / 98$ & 0.31 & -1.93 & 08/20/98 & 0.66 & 0.51 & 08/20/98 & -0.49 & 1.21 \\
\hline $01 / 21 / 98$ & 0.35 & -1.27 & $08 / 27 / 98$ & 0.70 & 0.53 & $08 / 27 / 98$ & -0.53 & 1.29 \\
\hline $01 / 28 / 98$ & 0.35 & -0.36 & 09/03/98 & 0.73 & 0.55 & 09/03/98 & -0.58 & 1.39 \\
\hline $02 / 06 / 98$ & n.a. & n.a. & 09/10/98 & 1.41 & 0.75 & 09/10/98 & -0.56 & 1.31 \\
\hline 02/13/98 & n.a. & n.a. & 09/17/98 & 1.41 & 0.75 & 09/17/98 & -0.59 & 1.14 \\
\hline $02 / 20 / 98$ & n.a. & n.a. & $09 / 24 / 98$ & 1.41 & 0.73 & $09 / 24 / 98$ & n.a. & n.a. \\
\hline
\end{tabular}

Notes: The estimates of $a$ and $d$ are computed from 53-week samples with the indicated starting date. For each country, the estimate in the first line repeats the figures in table 1.2. The algorithm used to map data to parameters cannot be used when the estimate of the first-order autocorrelation of $\Delta s_{t}$ is positive. The n.a. entries flag samples in which the estimate of this autocorrelation is positive. 
little, in light of the huge confidence intervals in the previous table. In the Philippines, the estimate of $d$ ranges from about 0.5 to 0.7 ; in Thailand, the range is about 1.1 to 1.4. Moreover, the estimate of $a$ does not fall, which one might expect if Thailand systematically raised interest rates in response to incipient exchange rate depreciation in the early but not the later parts of the sample. Thus this exercise is not particularly helpful in interpreting the results for Thailand.

One estimate that is quite sensitive to the sample is that for $d$, for Korea. The estimated value rises rapidly, from -8.99 to -0.36 . A possible rationalization of this pattern is that as a country stabilizes, exchange rate risk becomes insensitive to the level of the interest rate. Perhaps $d=0$ in developed countries, or at least in countries without credit rationing (see Furman and Stiglitz 1998). Clearly, however, this is a speculative interpretation, and the large confidence intervals in table 1.2 make it reasonable to attribute the wide variation to sampling error in estimation of $d$.

\subsection{Conclusions}

We have formulated and estimated a model that allows for interest rate shocks to either appreciate or depreciate exchange rates. Using weekly data, we have estimated a special case of the model using data from Korea, the Philippines, and Thailand. We have found that an exogenous increase in interest rates caused exchange rate appreciation in Korea and the Philippines, depreciation in Thailand. The estimates are, however, quite noisy.

One set of priorities for future work is to use higher frequency data, allow for richer shock processes, and use more efficient estimation techniques. A second is to allow for the possibility that for some period of time, monetary policy was destabilizing, with a switch in the sign of the interest rate reaction function necessary for stabilization. A third is to bring additional variables, such as the level of foreign reserves, into the model. A final, and broad, aim of our future work is to use our knowledge of the relationship between interest rates and exchange rates to analyze the macroeconomic effects of monetary policy in countries undergoing currency crises.

\section{Appendix}

\section{Mapping from Moments to Model Parameters}

Let $u_{d t}$ and $u_{m t}$ follow random walks

$$
u_{d t}=u_{d t-1}+e_{d t}, \quad u_{m t}=u_{m t-1}+e_{m t},
$$


where $e_{d t}$ and $e_{m t}$ are vector white noise. Then the solution of the model is

$$
s_{t}=-\left(a^{-1}+1-d\right) u_{m t}+(1-d) u_{m t-1}+\left[1+(1-d)^{-1} a^{-1}\right] u_{d t}-u_{d t-1} .
$$

Define $\tilde{u}_{d t}=(1-d)^{-1} u_{d t}, \tilde{e}_{d t}=(1-d)^{-1} e_{d t}, \delta=1-d, \alpha=a^{-1}$. Rewrite equation (A2) as

$$
i_{t}=\tilde{u}_{d t-1}+e_{m t}, s_{t}=(\alpha+\delta)\left(\tilde{u}_{d t}-u_{m t}\right)-\delta\left(\tilde{u}_{d t-1}-u_{m t-1}\right) .
$$

Suppose we sample data every $n$ periods ( $n=5$ in the computations in the text). Then

$$
\begin{gathered}
i_{t}-i_{t-n}=\tilde{e}_{d t-1}+\tilde{e}_{d t-2}+\ldots+\tilde{e}_{d t-n}+e_{m t}-e_{m t-n} . \\
s_{t}-s_{t-n}=(\alpha+\delta)\left(\tilde{e}_{d t}-e_{m t}\right)+\alpha\left(\tilde{e}_{d t-1}-e_{m t-1}\right) \\
\quad+\ldots+\alpha\left(\tilde{e}_{d t-n+1}-e_{m t-n+1}\right)-\delta\left(\tilde{e}_{d t-n}-e_{m t-n}\right) .
\end{gathered}
$$

Define $\Delta^{n} i_{t}=i_{t}-i_{t-n}, \Delta^{n} S_{t}=s_{t}-s_{t-n}, \tilde{\sigma}_{m d}=\operatorname{cov}\left(e_{m t}, \tilde{e}_{d t}\right), \tilde{\sigma}_{d}^{2}=\operatorname{var}\left(\tilde{e}_{d t}\right), \sigma_{m}^{2}=$ $\operatorname{var}\left(e_{m t}\right)$. Then

$$
\begin{gathered}
\operatorname{var}\left(\Delta^{n} i\right)=n \tilde{\sigma}_{d}^{2}+2 \sigma_{m}^{2}-2 \tilde{\sigma}_{m d}, \\
\operatorname{var}\left(\Delta^{n} S\right)=\left(n \alpha^{2}+2 \alpha \delta+2 \delta^{2}\right)\left(\tilde{\sigma}_{d}^{2}+\sigma_{m}^{2}-2 \tilde{\sigma}_{m d}\right), \\
\operatorname{cov}\left(\Delta^{n} i, \Delta^{n} S\right)=[(n-1) \alpha-\delta] \tilde{\sigma}_{d}^{2}-(\alpha+2 \delta) \sigma_{m}^{2} \\
-[(n-1) \alpha-\alpha-3 \delta] \tilde{\sigma}_{m d}, \\
\operatorname{cov}\left(\Delta^{n} S, \Delta^{n} S_{-n}\right)=-\delta(\alpha+\delta)\left(\tilde{\sigma}_{d}^{2}+\sigma_{m}^{2}-2 \tilde{\sigma}_{m d}\right), \\
\operatorname{cov}\left(\Delta^{n} i, \Delta^{n} S_{-n}\right)=(\alpha+\delta)\left(\tilde{\sigma}_{d}^{2}+\sigma_{m}^{2}-2 \tilde{\sigma}_{m d}\right) .
\end{gathered}
$$

Equations (A5) to (A9) were used to solve for $\tilde{\sigma}_{d}^{2}, \sigma_{m}^{2}, \tilde{\sigma}_{m d}, \alpha$, and $\delta$. From these, $a$ and $d$ can be computed. When $\operatorname{cov}\left(\Delta^{n} s, \Delta^{n} S_{-n}\right)<0$, a quadratic that is used to solve for $\alpha$ is guaranteed to have one negative and one positive root. We chose the root consistent with stable monetary policy: the negative root when the estimate of $d$ was greater than 1, the positive root otherwise.

\section{Description of Bootstrap Technique}

The bootstrap confidence intervals in table 1.2 were based on 5,000 replications of the following procedure. Each replication was based on an artificial sample constructed by sampling, with replacement, nonoverlapping blocks of size 6 , from the actual data. For the larger sample ( $T=53$ weeks), we sampled the blocks from a sample of 54 weeks. We used 54 rather than 53 weeks so that the sample contained an integral multiple of blocks; the 54 weeks consisted of the 53 used in the estimation plus an additional week at 
the end of the sample (e.g., 12/17/97-12/23/98 for Korea). In the smaller sample ( $T=27$ weeks), we sampled the blocks from a sample of 30 weeks, adding three weeks to the data used in estimates reported in the table (e.g., 12/17/97-07/08/98 for Korea).

For each of the 5,000 samples, we applied the procedure used to obtain the point estimates, to samples of size 53 or 27 . We sorted the results from lowest to highest. For the autocorrelations in table 1.1, the confidence intervals were obtained by dropping the lowest and highest 5 percent of the results (i.e., the 500 lowest and 500 highest). For the point estimates in table 1.2, we first dropped all results in which (1) the point estimate of the firstorder autocorrelation of $\Delta s_{t}$ was positive or less than -0.5 , or (2) the point estimate of $\operatorname{var}\left(e_{d t}\right)$ or $\operatorname{var}\left(e_{m t}\right)$ was negative. The confidence intervals were then obtained by dropping the lowest and highest 5 percent of the remaining results. The number of observations that remained after dropping those with inadmissable point estimates were as follows: Korea, 3,318 $(T=53)$ and 2,746 $(T=27)$; the Philippines, 1,977 $(T=53)$ and 2,728 $(T=27)$; Thailand, 1, $661(T=53)$ and $2,285(T=27)$. The relative paucity of remaining observations in the Philippines and Thailand for $T=53$ results from a relatively large number of bootstrap samples in which the point estimate of the first-order autocorrelation of $\Delta s_{t}$ was positive.

\section{References}

Basurto, Gabriela, and Atish Ghosh. 2000. The interest rate-exchange rate nexus in currency crises. IMF Working Paper no. WP/00/19. Washington, D.C.: International Monetary Fund, February.

Cho, Dongchul, and Kiseok Hong. 2002. Currency crisis of Korea: Internal weakness or external independence? In Regional and global capital flows: Macroeconomic causes and consequences, ed. Takatoshi Ito and Anne O. Krueger, 337-73. Chicago: University of Chicago Press.

Cho, Dongchul, and Kenneth D. West. 2000. The effect of monetary policy in exchange rate stabilization in post-crisis Korea. In The Korean crisis: Before and after, ed. I. Shin, 255-86. Seoul: Korea Development Institute.

Dekle, Robert, Cheng Hsiao, and Siyan Wang. 2001. Interest rate stabilization of exchange rates and contagion in the Asian crisis countries. In Financial crises in emerging markets, ed. Reuven Glick, Ramon Moreno, and Mark Maury Spiegel, 347-83. Cambridge, England: Cambridge University Press.

Di Bella, Gabriel. 2000. Exchange rate stabilization in Mexico and Thailand: Was the tight monetary policy effective? University of Wisconsin, Department of Economics. Unpublished Manuscript.

Eichenbaum, Martin, and Charles L. Evans. 1995. Some empirical evidence on the effects of shocks to monetary policy on exchange rates. Quarterly Journal of Economics 110 (4): 975-1009.

Fischer, Stanley. 1998. The Asian crisis: A view from the IMF. Address at the Midwinter Conference of the Bankers' Association for Foreign Trade. 22 January, 
Washington, D.C. Available at [www.imf.org/external/np/speeches/1998/012298. htm].

Furman, Jason, and Joseph E. Stiglitz. 1998. Economic crises: Evidence and insights from East Asia. Brookings Papers on Economic Activity, Issue no. 2:1-135. Washington, D.C.: Brookings Institution.

Goldfajn, Ilan, and Taimur Baig. 1998. Monetary policy in the aftermath of currency crises: The case of Asia. IMF Working Paper no. WP/98/170. Washington, D.C.: International Monetary Fund.

Goldfajn, Ilan, and Poonam Gupta. 1999. Does monetary policy stabilize the exchange rate following a currency crisis? IMF Working Paper no. WP/99/42. Washington, D.C.: International Monetary Fund.

Gould, David M., and Steven B. Kamin. 2000. The impact of monetary policy on exchange rates during financial crises. International Financial Discussion Paper no. 669. Washington, D.C.: Board of Governors of the Federal Reserve System.

Grilli, Vittorio, and Nouriel Roubini. 1996. Liquidity models in open economies: Theory and empirical evidence. European Economic Review 40 (3-5): 847-59.

International Monetary Fund. 1997a. Thailand letter of intent, 14 August 1997. Available at [http://www.imf.org/external/np/loi/081497.htm].

- 1997b. Thailand letter of intent, 25 November 1997. Available at [http:// www.imf.org/external/np/loi/112597.htm].

. 1998. Thailand letter of intent and memorandum on economic policies, 24 February 1998. Available at [http://www.imf.org/external/np/loi/022498.htm].

Radelet, Steven, and Jeffrey D. Sachs. 1998. The East Asian financial crisis: Diagnosis, remedies, prospects. Brookings Papers on Economic Activity, Issue no. 1:174. Washington, D.C.: Brookings Institution.

\section{Comment Robert Dekle}

During the recent East Asian currency crisis, the relationship between exchange rates and interest rates became a topic of intense controversy. The traditional view stresses that tight monetary policies are necessary to support the exchange rate: higher interest rates raise the returns that an investor obtains from investing in the country, reduce capital flight, and discourage speculation. However, recently some prominent economists (Radelet and Sachs 1998; Furman and Stiglitz 1998) have argued a revisionist view that a rise in interest rates depreciates the exchange rate.

The revisionist view is that under the unique conditions of a financial panic, tight monetary policies and high interest rates would result in capital outflows and exchange rate depreciation. That is, high interest rates cause a financial implosion and raise default probabilities, causing capital to flow out and weakening the currency. High rates can compromise the net worth of many firms, and the bankruptcy of these firms can have adverse effects on the net worth of the firms' creditors, especially that of domestic 
banks. In turn, as these banks fail and cut lending, credit can become constrained, further raising bankruptcies and causing capital to flee.

Recently, there has been much empirical work examining the interest rate-exchange rate nexus in emerging-market countries during crisis. This work can be divided into those using high-frequency (daily or weekly) time series data and those using cross-country or panel data. As to the work using time series data, the results have generally been mixed. Goldfajn and Baig (1998) and Dekle, Hsiao, and Wang (1999) find sharp evidence that interest rates appreciate exchange rates, whereas Gould and Kamin (2000) are unable to find a reliable relationship between interest rates and exchange rates. As to the work using cross-country or panel data, the results are again mixed. Goldfajn and Gupta (1999) find that high interest rates appreciate the exchange rate, but only in countries with strong banking sectors. Furman and Stiglitz (1998) find that if the sample is restricted to low-inflation countries - which include East Asia - high interest rates lead to exchange rate depreciations.

The paper by Kenneth West and Dongchul Cho is a significant advance over the earlier work that uses time series data. The earlier work was nonstructural and simply ran vector autoregressions (VARs) of nominal exchange rates on nominal short-term interest rates. The work tried to infer causality by testing whether changes in interest rates temporally preceded (led) changes in exchange rates. The results from these VARs were fragile and depended critically on sample frequency (daily or weekly), sample period (starting and ending dates), and lag length. Moreover, given that both exchange rates and interest rates are endogenous, forward-looking variables, it was difficult to infer causality from simple leads and lags.

West and Cho's paper significantly improves upon the earlier time series work. The authors develop and estimate an explicit structural model of the interest rate-exchange rate nexus. The West and Cho model contains three equations. In addition to the usual uncovered interest rate parity equation (their equation [1]), the model contains a monetary policy equation, in which monetary authorities react to expected exchange rate depreciations (equation [2]), and an equation relating the exchange rate risk premium to the interest rate (equation [3]). Given explicit assumptions about expectations formation (model consistent, rational expectations), the timing of monetary policy, and the nature of shocks, the parameters of the model can be identified. The estimation of these equations allows for an explicit test of the revisionist view: whether the risk premium increases in response to a rise in interest rates, and if so, whether the response is strongly positive enough to warrant a depreciation of the exchange rate.

West and Cho estimate their model on weekly data for Korea, the Philippines, and Thailand. In Korea, exchange rate risk premiums are found to be negatively related to interest rates, thus supporting the traditional view of the relationship between interest rates and exchange rates. In the Philip- 
pines, risk premiums are positively related to interest rates, but not strongly positive enough to warrant the reversal of the traditional view. In Thailand, risk premiums are strongly positively related to interest rates, thus supporting the revisionist view. West and Cho vary their sample starting dates, and although their parameter estimates are somewhat unstable, their conclusions, based on their point estimates, are generally robust.

Some international economists may be surprised by West and Cho's success in finding a relationship between exchange and interest rates, especially in emerging markets during crises. After all, it is well known that, in general, there is no stable empirical short-run relationship between exchange and interest rates, even in industrial countries, in tranquil times (Frankel and Rose 1995). Nominal exchange rates move as if they are a random walk. On closer examination, however, West and Cho's results appear consistent with the earlier findings. In particular, West and Cho admit that their standard error bands are very wide; for example, the sensitivity of Korea's risk premium to the interest rate is -8.87 , with a 90 percent confidence interval of -27.7 to 14.2 . Varying the sample period results in a different sensitivity, implying some parameter instability, just as in earlier findings. Moreover, given the large standard error bands, should the West and Cho model be used to predict exchange rates, the predictive performance (root mean squared error) of their model would probably be inferior to that of a simple random walk.

I have two minor quibbles with the underlying assumptions of West and Cho's model. First, the solution to West and Cho's model imposes rational expectations. Thus, agents are assumed to know not only the model, but the parameters and the shock processes of the model as well. Although this may be a reasonable assumption for industrialized economies in tranquil times, for emerging markets in crisis, the rational expectations assumption may be too strong. For most East Asian countries, the crisis was an unexpected, one-off event. The residents in these countries had no experience with crisis regimes. Thus it is unlikely that the residents would know or be able to estimate the parameters of the model.

Second, in West and Cho's monetary policy reaction function, equation (2), the monetary authorities' interest rate rule is assumed to depend solely on the expected depreciation rate. As the authors acknowledge, during the Asian crisis the monetary authorities also cared about additional variables, such as the levels of economic activity and foreign exchange reserves. For example, during the crisis period in Korea, the authorities were carefully observing daily bankruptcies in the Seoul area, as a measure of economic activity, and the level of foreign exchange reserves. Figure 1C.1 shows that during the crisis period, the authorities' monetary control variable, the overnight call rate, was positively correlated with daily bankruptcies and negatively correlated with reserves.

Strong assumptions, however, are necessary in any useful model. To un- 


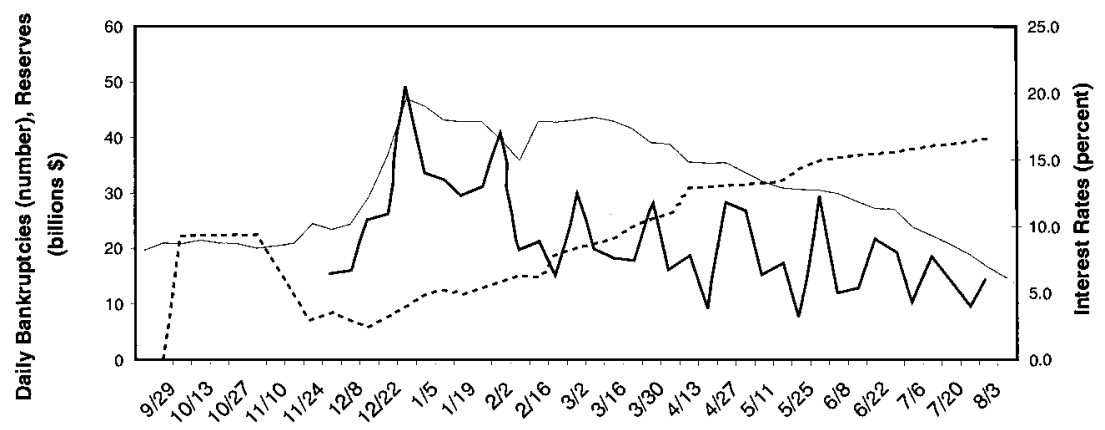

— Bankruptcies .... Reserves -_ Overnight Call Rate

Fig. 1C.1 Korea: Bankruptcies, reserves, and interest rates

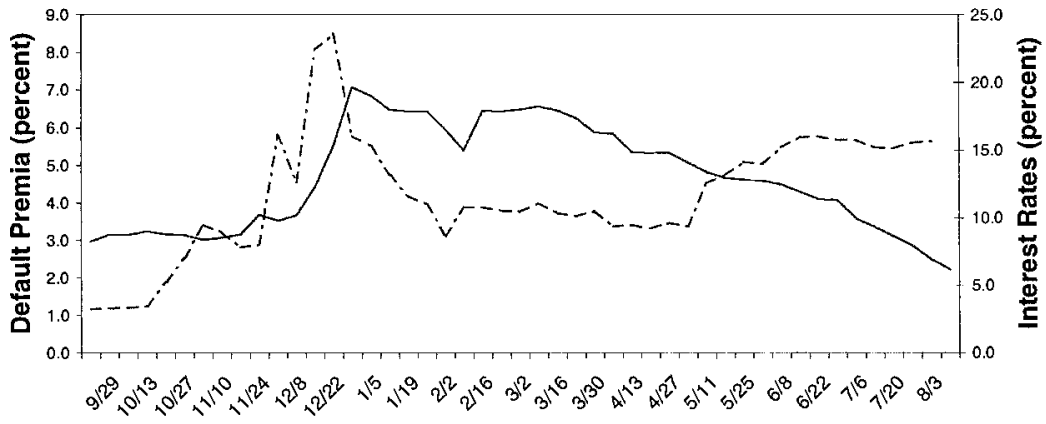

----Default Premia —-Overnight Call Rate

Fig. 1C.2 Korea: Default premia and interest rates

derscore the usefulness of the West and Cho model in understanding the interest rate-exchange rate nexus during the Asian crisis, examine figure 1C.2. The figure shows the correlation between the Korean overnight call rate and the default premiums on Korean sovereign bonds. From the figure it is difficult to draw any firm conclusions about the relationship between interest rates and the default premiums. The default premiums are positively correlated with the interest rate, thus tending to support the revisionist view. However, the default premiums temporally lead the interest rate, rather than lagging, which casts doubt on whether the interest rate is causing changes in the default premiums. West and Cho's model shows that if monetary authorities are, as it were, leaning against the wind in expected exchange rate depreciations, the interest rate rises, and the exchange rate appreciates with a lag in response to a risk premium shock (their figures 1.3 and 1.4). Interest rates and exchange rates are positively correlated, and this 
correlation is a result of monetary authorities' actively raising the interest rate. Thus, if observed default premiums on Korean bonds are contemporaneously correlated with risk premium shocks, the pattern observed in figure 1C.2 is certainly consistent with the traditional view of the interest rateexchange rate nexus.

In sum, the West and Cho paper is very useful in understanding the interest rate-exchange rate nexus during the East Asian crisis. It should become the standard reference on this topic.

\section{References}

Dekle, R., C. Hsiao, and S. Wang. 1999. Interest rate stabilization of exchange rates and contagion in the Asian crisis countries. University of Southern California. Unpublished Manuscript.

Frankel, J., and A. Rose. 1995. Empirical research on nominal exchange rates. In Handbook of international economics, Vol. 3, ed. G. Grossman and K. Rogoff, 1689-721. Amsterdam: North-Holland.

Furman, J., and J. Stiglitz. 1998. Economic crisis: Evidence and insights from East Asia. Brookings Papers on Economic Activity, Issue no. 2:1-135. Washington, D.C.: Brookings Institution.

Goldfajn, I., and T. Baig. 1998. Monetary policy in the aftermath of currency crisis: The case of Asia. IMF Working Paper no. WP/98/170. Washington, D.C.: International Monetary Fund.

Goldfajn, I., and P. Gupta. 1999. Does monetary policy stabilize the exchange rate following a currency crisis? IMF Working Paper no. WP/99/42. Washington, D.C.: International Monetary Fund, March.

Gould, D. M., and S. Kamin. 2000. The impact of monetary policy on exchange rates during financial crisis. International Finance Discussion Paper no. 699. Washington, D.C.: Board of Governors of the Federal Reserve System.

Radelet, S., and J. Sachs. 1998. The East Asian financial crisis: Diagnosis, remedies, prospects. Brookings Papers on Economic Activity, Issue no. 1:1-74. Washington, D.C.: Brookings Institution.

\section{Discussion Summary}

Jeffrey Shafer suggested that specific histories and observations are often helpful in terms of understanding economic relationships. He added that an interest rate increase often stabilizes the exchange rate, whereas a subsequent premature lowering of the interest rate will destroy credibility.

Yung Chul Park made reference to figure 1.5 of the paper and noted that Korean interest rates and exchange rates were stabilized around February 1998. He argued that debt restructuring was the cause of the observed stabilization.

Martin Feldstein remarked that the real question is not just whether the 
interest rate can stabilize the currency but whether it makes sense to let the interest rate increase when we consider the adverse effects on the economy.

Andrew $K$. Rose remarked that he was generally suspicious of case-study approaches, although he agreed with the conclusion of the paper, that interest rate defense does seem to work.

Martin Feldstein pointed to Sweden and Turkey as examples of regions where interest rate defense didn't work. Allan Drazen concurred and emphasized the issue of sample selection bias.

Robert P. Flood suggested that the authors take account of differences in fundamentals.

Michael M. Hutchison remarked that the argument for or against interest rate defense depends on the state of the financial sector and the debt positions of the country. He added that the type of debt structure matters as well.

Edwin M. Truman made a reference to Turkey's failed interest rate defense and remarked that the political implications of an interest rate defense should not be overlooked. Shafer added that Turkey's unwillingness to supply reserves to banks that were being squeezed in the interbank market for the financial sector caused the failure.

Andrew Berg pointed to the difference between the defense of a peg and a crisis in a free float. He added that the degree of capital mobility is essential in thinking about the interest rate defense.

Peter B. Kenen remarked that the timing of the introduction of the IMF programs differed across countries under attack. He concurred with Truman and asked whether the exchange rate depreciation or the interest rate increase will hurt the economy the most.

Kenneth D. West agreed with Shafer and Park that there is useful country-specific information. He agreed with Feldstein that the fundamental question is what constitutes good monetary policy; the Cho and West paper considers an important element of the answer to this question. He emphasized that the Cho and West paper allows for interest rate hikes to be associated with either exchange rate appreciations or depreciations. In response to Rose, he pointed out that the Cho and West paper provides for the possibility that variation in exchange rate risk premiums dominates exchange rate movements, thus allowing a stronger result than the work that Rose cited on the interest rate defense during crises. He agreed with the comments of several participants that in future work it would be useful to study countries with failed stabilization programs. 
